\title{
Effects of E-Beam Irradiation on the Chemical, Physical, and Electrochemical Properties of Activated Carbons for Electric Double-Layer Capacitors
}

\author{
Min-Jung Jung, Mi-Seon Park, and Young-Seak Lee \\ Department of Applied Chemistry and Biological Engineering, Chungnam National University, Daejeon 305-764, Republic of Korea \\ Correspondence should be addressed to Young-Seak Lee; youngslee@cnu.ac.kr
}

Received 5 March 2015; Accepted 27 March 2015

Academic Editor: Jae-Ho Kim

Copyright (C) 2015 Min-Jung Jung et al. This is an open access article distributed under the Creative Commons Attribution License, which permits unrestricted use, distribution, and reproduction in any medium, provided the original work is properly cited.

\begin{abstract}
Activated carbons (ACs) were modified via e-beam irradiation at various doses for use as an electrode material in electric doublelayer capacitors (EDLCs). The chemical compositions of the AC surfaces were largely unchanged by the e-beam irradiation. The ACs treated with the e-beam at radiation doses of $200 \mathrm{kGy}$ exhibited higher nanocrystallinity than the untreated ACs. The specific surface areas and pore volumes of the e-beam irradiated ACs were also higher than those of the untreated ACs. These results were attributed to the transformation and degradation of the nanocrystallinity of the AC surfaces due to the e-beam irradiation. The specific capacitance of the ACs treated with the e-beam at radiation doses of $200 \mathrm{kGy}$ increased by $24 \%$ compared with the untreated ACs, and the charge transfer resistance of the ACs was decreased by the e-beam irradiation. The enhancement of the electrochemical properties of the e-beam irradiated ACs can be attributed to an increase in their specific surface area and surface crystallinity.
\end{abstract}

\section{Introduction}

Electron-beam (e-beam) irradiation has been of interest in many research fields, such as polymerization and the modification of polymers, lithography, and food science [1-5]. Electron-beam irradiation changes the structures of polymer chains, which induce chain scission, cross-linking, or radical formation [6-8]. Recently, some researchers have attempted to apply e-beam irradiation to various carbon materials ( $\mathrm{sp}^{3}$ or $\mathrm{sp}^{2}$ materials), such as carbon nanotubes, graphene, and diamond [9-11]. It is usually intended to study a damage or deposition of carbon materials during analyzing by equipment using the e-beam including scanning electron microscopy (SEM), transmission electron microscopy (TEM), focused ion beam (FIB), and atomic force microscopy (AFM) [12-14]. Generally, e-beam irradiation causes the hemolytic cleavage of $\mathrm{C}-\mathrm{C}$ and $\mathrm{C}-\mathrm{H}$ bonds on polymer surfaces. The resulting alkyl radicals are not stable and undergo a complex series of reactions that lead to crosslinking, chain scissions, oxidation, and the formation of
$\mathrm{C}=\mathrm{C}$ bonds [15]. E-beam irradiation is a simple, solvent-free, and ambient-temperature electron-beam-based modification method [16]. Therefore, it is expected that e-beam irradiation is a viable technology for the modification of carbon material surfaces for electrochemical applications, such as electrical double-layer capacitors (EDLCs).

In this study, e-beam irradiation was applied to modify activated carbons (ACs) for use as electrode materials in EDLCs. The changes in the physical and chemical properties of the AC surfaces after modification were characterized and analyzed, and the effects of e-beam irradiation on the electrochemical performance of the ACs were also investigated. Through this study, the potential use of the electron-beam irradiation was evaluated.

\section{Materials and Methods}

2.1. E-Beam Irradiation of Activated Carbons. In this study, phenol-based AC (MSP-20, Kansai Coke and Chemicals Co., Ltd., Japan) was used. For the e-beam treatment, $2 \mathrm{~g}$ of the 
AC was poured into sample bottles. The sample bottles were placed on a tray for e-beam radiation. E-beam irradiation was performed at 100, 200, 300, and $500 \mathrm{kGy}$. The prepared samples were named according to the e-beam radiation dose as E100-AC, E200-AC, E300-AC, and E500-AC, and the untreated AC was named R-AC.

2.2. Physicochemical Characterization. To investigate the changes in the functional groups on the surfaces of the untreated and e-beam irradiated ACs, X-ray photoelectron spectroscopy (XPS, VG Multilab 2000, Thermo VG Scientific, $\mathrm{UK}$ ) analysis was performed using $\mathrm{Al} \mathrm{K} \alpha$ radiation. XPS elemental analysis was used to determine the average elemental contents in the sample. The C1s peaks were deconvoluted into several pseudo-Voigt functions (sums of a GaussianLorentzian function) using a peak analysis program obtained from Unipress Co., USA. The pseudo-Voigt function is given by [17]

$$
\begin{aligned}
& F(E)=H\left[(1-S) \exp \left(-\ln (2)\left(\frac{E-E_{0}}{R_{\mathrm{FWHM}}}\right)^{2}\right)\right. \\
& \left.+\frac{S}{1+\left(\left(E-E_{0}\right) / R_{\mathrm{FWHM}}\right)^{2}}\right],
\end{aligned}
$$

where $F(E)$ is the intensity at energy $E, H$ is the peak height, $E_{0}$ is the peak center, $R_{\mathrm{FWHM}}$ is the full width at halfmaximum (FWHM), and $S$ is the shape function related to the symmetry and the Gaussian-Lorentzian mixing ratio. The FWHM of the $\mathrm{Cls}$ peak was $1.3 \mathrm{eV}$.

To characterize the crystalline structure of the ACs, the Raman spectra were recorded using a HORIBA JobinYvon LabRam Aramis spectrometer (HORIBA Jobin-Yvon, Edison, NJ). The $514 \mathrm{~nm}$ arrow of an Ar-ion laser was used as the excitation source. The $\mathrm{G}$ and $\mathrm{D}$ peak positions and the $I_{\mathrm{D}} / I_{\mathrm{G}}$ intensity ratio are widely used for identifying the type of carbon and characterizing the carbon structure. The resulting Raman spectra were deconvoluted into $G$ and D bands using Gaussian functions.

The pore structures of the samples were assessed using $\mathrm{N}_{2}$ adsorption at $77 \mathrm{~K}$ (ASAP2020, Micromeritics, USA). The specific surface areas of the samples were evaluated using the Brunauer-Emmett-Teller (BET) equation. In addition, the pore size distributions of the samples were determined using density functional theory (DFT).

2.3. Electrochemical Characterization. EDLC electrodes were fabricated by mixing $80 \mathrm{wt} \%$ AC, $10 \mathrm{wt} \%$ carbon black (Super P, Timcal Ltd., Switzerland), and a $10 \mathrm{wt} \%$ solution of polyvinylidene fluoride (PVDF, Aldrich, USA) in $\mathrm{N}$-methyl pyrrolidone (NMP, Aldrich, USA) to form a slurry, which was then painted onto a titanium plate. The AC-based electrodes were electrochemically characterized using a computer-controlled potentiostat/galvanostat (Ivium Technologies, Netherlands) equipped with a three-electrode assembly. The AC-based electrode was used as the working electrode, and $\mathrm{Ag} \mid \mathrm{AgCl}$ was used as the reference electrode. A platinum plate was used as the counter electrode. Cyclic

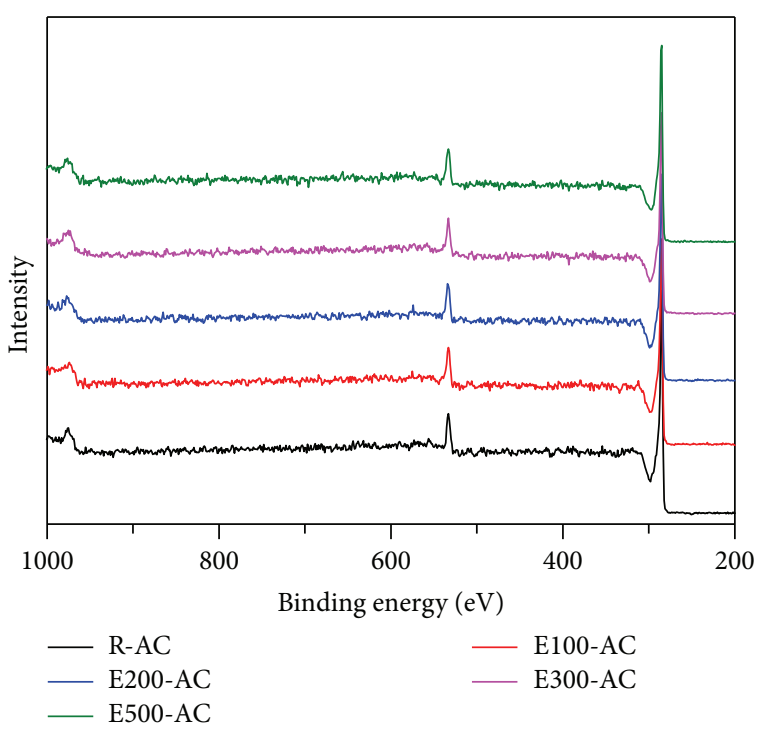

FIGURE 1: XPS wide scan spectra of e-beam irradiated ACs.

TABLE 1: XPS surface elemental analysis parameters of e-beam irradiated ACs.

\begin{tabular}{lccc}
\hline \multirow{2}{*}{ Sample } & \multicolumn{2}{c}{ Elemental contents (atomic percent) } & O/C (\%) \\
& $\mathrm{C}$ & $\mathrm{O}$ & \\
\hline R-AC & 92.7 & 7.3 & 7.87 \\
E100-AC & 93.4 & 6.6 & 7.07 \\
E200-AC & 92.9 & 7.1 & 7.64 \\
E300-AC & 93.3 & 6.7 & 7.18 \\
E500-AC & 93.7 & 6.3 & 6.72 \\
\hline
\end{tabular}

voltammetry $(\mathrm{CV})$ of the electrode materials was performed over a potential range of 0 to $1 \mathrm{~V}$ at scan rates of 5 and $50 \mathrm{mV} \mathrm{s}^{-1}$ in a $1 \mathrm{M} \mathrm{H}_{2} \mathrm{SO}_{4}$ electrolyte.

An AC impedance spectrum analyzer was employed to measure and analyze the impedance behavior of the capacitors. In this work, the measurements were conducted at $0 \mathrm{~V}$ with an AC potential amplitude of $5 \mathrm{mV}$ in the frequency range of $10 \mathrm{mHz}$ to $100 \mathrm{kHz}$.

\section{Results and Discussion}

3.1. Changes in the Surface Chemical Properties of the EBeam Irradiated Activated Carbons. XPS elemental analysis was conducted to compare the surface chemical properties of the ACs before and after e-beam irradiation. As can be observed in Table 1 and Figure 1, two main peaks are identified, marked C1s and O1s. The peaks at approximately 970-1 $000 \mathrm{eV}$ are the oxygen Auger peaks $[18,19]$. As shown in Table 1, the samples are almost identical in terms of elemental composition. The oxygen content of R-AC was found to be approximately 7.3 at $\%$, while the e-beam irradiated ACs had oxygen contents of 6.3-7.1 at \%. Therefore, it is concluded that e-beam irradiation does not have a significant effect on the chemical composition of the AC surfaces. 
TABLE 2: C1s peak parameters of e-beam irradiated ACs.

\begin{tabular}{|c|c|c|c|c|c|c|}
\hline \multirow{2}{*}{ Component } & \multirow{2}{*}{ Peak position $(\mathrm{eV})$} & \multicolumn{5}{|c|}{ Concentration (\%) } \\
\hline & & $\mathrm{R}-\mathrm{AC}$ & E100-AC & E200-AC & E300-AC & E500-AC \\
\hline \multicolumn{7}{|l|}{$\mathrm{C}(1)$} \\
\hline $\mathrm{C}-\mathrm{C}\left(\mathrm{sp}^{2}\right)$ & 284.5 & 64.1 & 73.2 & 74.6 & 70.3 & 66.3 \\
\hline \multicolumn{7}{|l|}{$\mathrm{C}(2)$} \\
\hline $\mathrm{C}-\mathrm{C}\left(\mathrm{sp}^{3}\right)$ & 285.4 & 19.9 & 16.5 & 11.9 & 18.4 & 23.9 \\
\hline \multicolumn{7}{|l|}{$C(3)$} \\
\hline $\mathrm{C}-\mathrm{O}$ & 286.4 & 11.8 & 7.5 & 10.4 & 8.3 & 7.7 \\
\hline \multicolumn{7}{|l|}{$\mathrm{C}(4)$} \\
\hline $\mathrm{C}=\mathrm{O}$ & 287.4 & 4.2 & 2.8 & 3.1 & 3.0 & 2.1 \\
\hline
\end{tabular}

TABLE 3: Structure characteristics of e-beam irradiated ACs obtained by the Raman spectra deconvolution.

\begin{tabular}{lcccc}
\hline & & Intensity ratio & \\
& $I_{\mathrm{D} 1} / I_{\mathrm{G} 1}$ & $I_{\mathrm{D} 2} / I_{\mathrm{G} 2}$ & $I_{\mathrm{G} 2} / I_{\mathrm{G} 1}$ & 2.48 \\
R-AC & 1.86 & 1.16 & 2.36 & 2.36 \\
E200-AC & 1.54 & 0.96 & 1.85 & 2.85 \\
E500-AC & 1.75 & 1.24 & 2.51 \\
\hline
\end{tabular}

In particular, to investigate the changes in the chemical bonds of the ACs due to e-beam irradiation, untreated and ebeam irradiated ACs were analyzed using $\mathrm{Cls}$ deconvolution. The deconvolution results of the C1s peaks are shown in Figure 2. The Cls peaks of all samples were deconvoluted into four peaks at 284.5, 285.4, 286.4, and $287.4 \mathrm{eV}$, which correspond to $\mathrm{C}-\mathrm{C}\left(\mathrm{sp}^{2}\right), \mathrm{C}-\mathrm{C}\left(\mathrm{sp}^{3}\right), \mathrm{C}-\mathrm{O}$, and $\mathrm{C}=\mathrm{O}$, respectively [20]. The components, peak positions, and concentrations are also summarized in Table 2. In this study, E200-AC had the highest concentration of $\mathrm{C}-\mathrm{C} \mathrm{sp} \mathrm{s}^{2}$ bonds. The concentration of $\mathrm{C}-\mathrm{C} \mathrm{sp}^{2}$ bonds on the AC surfaces increased with e-beam irradiation up to $200 \mathrm{kGy}$, while the concentration of C-C $\mathrm{sp}^{3}$ bonds on the AC surfaces decreased. In contrast, when the e-beam irradiation was performed at above $200 \mathrm{kGy}$, the concentration of C-C $\mathrm{sp}^{2}$ bonds decreased and the C-C $\mathrm{sp}^{3}$ bonds increased. Thus, e-beam irradiation transformed and degraded the nanocrystals on the AC surfaces [21].

The Raman spectra were deconvoluted to acquire information about the changes in the carbon structure of the ACs due to e-beam irradiation and are shown in Figure 3. The Raman spectra for the ACs were almost similar; therefore, only the Raman spectra of R-AC, E200-AC, and E500-AC are shown in Figure 3. Four peaks were observed at approximately $1605 \mathrm{~cm}^{-1}$ (G1), $1530 \mathrm{~cm}^{-1}$ (G2), 1340-1355 cm $\mathrm{cm}^{-1}$ (D1), and $1280 \mathrm{~cm}^{-1}$ (D2). The D-peaks (D1 and D2) correspond to the amorphous domains, while the G-peaks (G1 and G2) correspond to the graphite domains. The peak at $1605 \mathrm{~cm}^{-1}$ ( $\mathrm{G}$ band) is attributed to the typical $\mathrm{C}-\mathrm{C}$ stretching modes in graphite. The peak observed at approximately 1340$1355 \mathrm{~cm}^{-1}$ was assigned to the D band (related to the defects and disorder in the carbon material), which is typical for disordered carbon [22]. The Raman spectra of R-AC, E200$\mathrm{AC}$, and E500-AC were almost identical; however, the Raman spectra of E200-AC had a more intense G1 peak than R-AC and E500-AC.
Table 3 shows the peak intensity ratios of $I_{\mathrm{D} 1} / I_{\mathrm{G} 1}, I_{\mathrm{D} 2} / I_{\mathrm{G} 2}$, $I_{\mathrm{G} 2} / I_{\mathrm{G} 1}$, and $L_{a}$ in the investigated spectral range, which provides important information about the structures of the carbon materials [20]. Based on the following equation, the crystalline size $\left(L_{a}\right)$ was calculated [23]:

$$
L_{a}=4.4 \times\left(\frac{I_{\mathrm{D} 1}}{I_{\mathrm{G} 1}}\right)^{-1} .
$$

It is commonly known that a lower $I_{\mathrm{D} 2} / I_{\mathrm{G} 2}$ ratio indicates a lower amorphous phase content in the carbon material, whereas a lower $I_{\mathrm{G} 2} / I_{\mathrm{G} 1}$ ratio indicates decreasing of the carbon in forms of clusters [24]. According to the Raman results, E200-AC contained the smallest amount of amorphous phase.

For the e-beam energies employed in this study, the primary effect of irradiation in graphitic or $\mathrm{sp}^{2}$ carbon materials is a result of the knock-on collisions of atoms with electrons, which generates vacancies and structural defects (or interstitials) [25]. In addition, the materials are far from thermal equilibrium, that is to say, nonequilibrium, and, under certain circumstances, they can fulfill the conditions for selforganized structure formation. Accordingly, the change in hybridization facilitates the structural transformation $\mathrm{sp}^{2+\delta}$, $\mathrm{sp}^{3} \leftrightarrow \mathrm{sp}^{2}, \mathrm{sp}^{2+\delta}$ (trigonal $\leftrightarrow$ mixed trigonal, tetrahedral) [26]. Therefore, the nanocrystallinity of the AC surface could be increased by e-beam irradiation.

3.2. Changes in the Textural Properties of E-Beam Irradiated Activated Carbons. Nitrogen adsorption analysis was performed at $77 \mathrm{~K}$ to examine the changes in the pore texture of the ACs after e-beam irradiation at different radiation doses. Table 4 provides detailed information about the textural properties of the e-beam irradiated ACs. It was observed that the specific surface area and total pore volume 


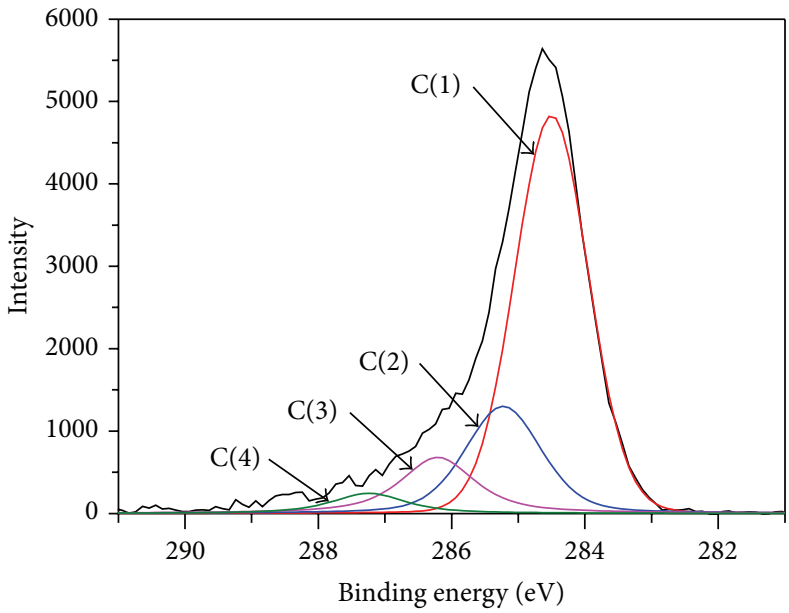

(a)

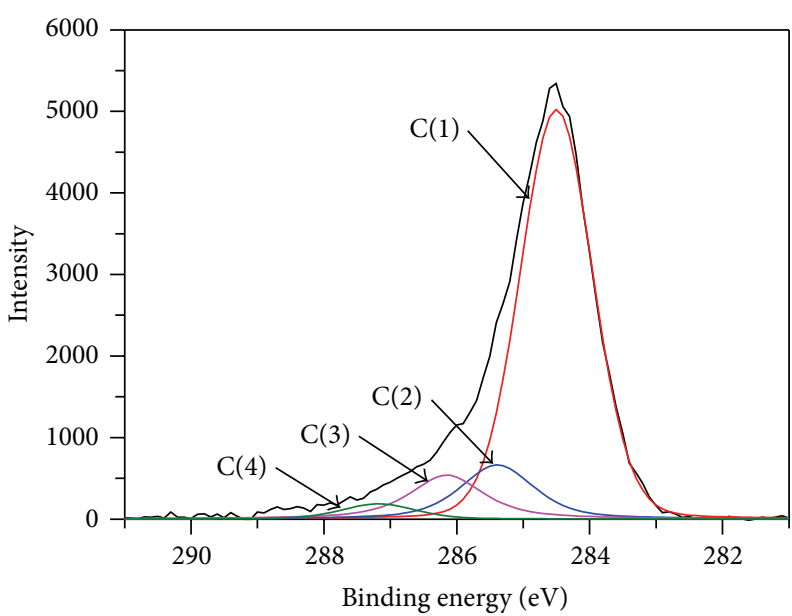

(c)

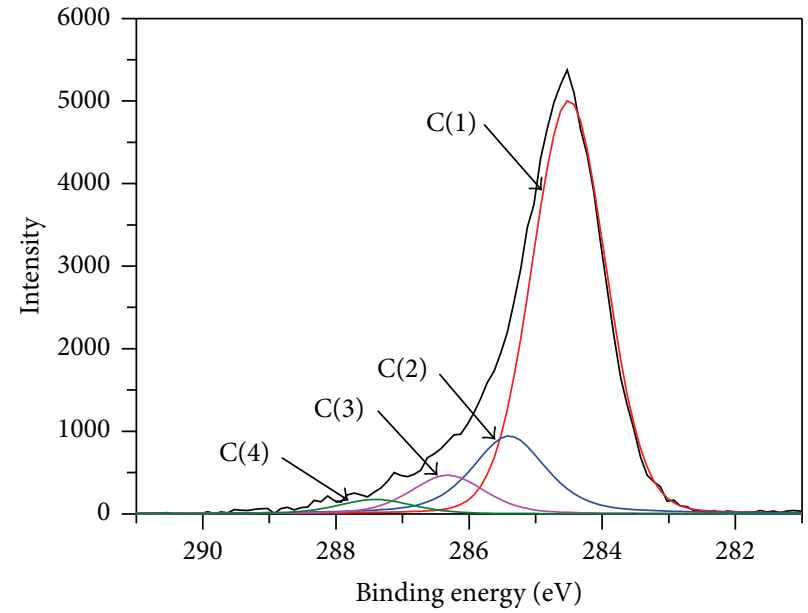

(b)

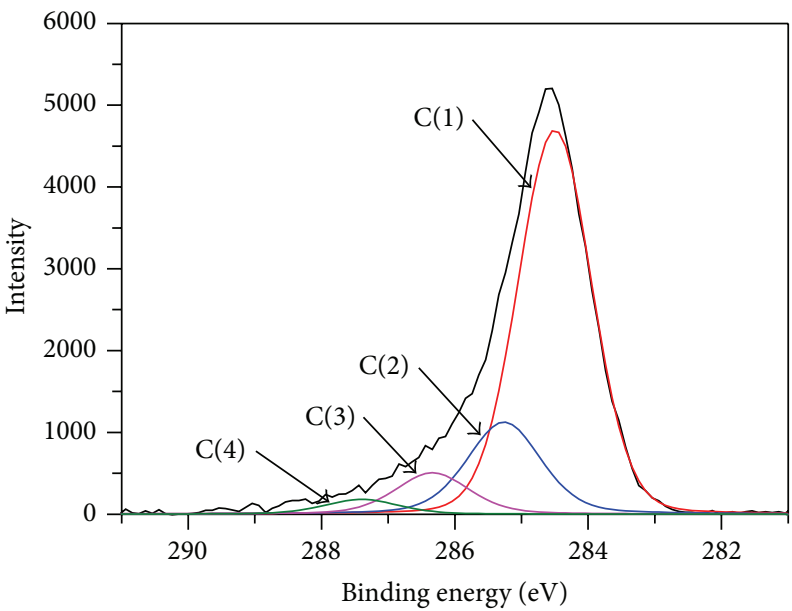

(d)

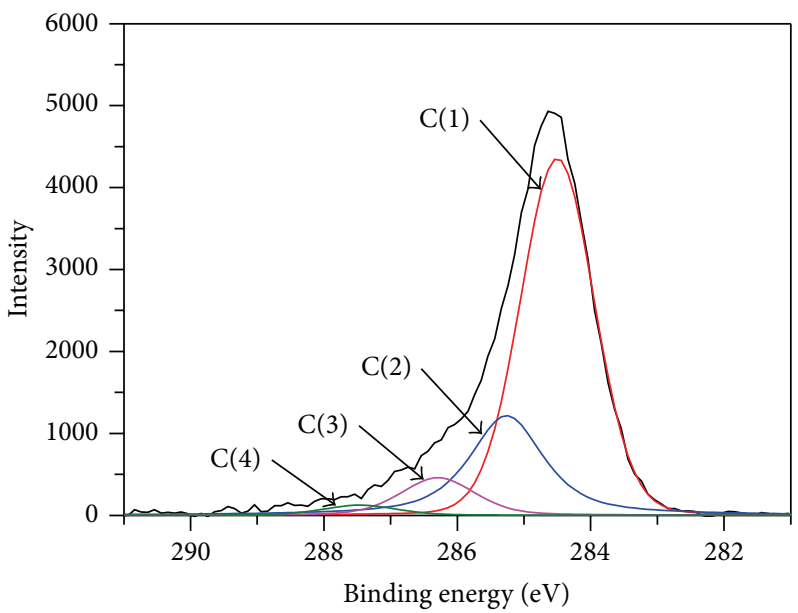

(e)

Figure 2: Deconvolution of the core level C1s spectra of (a) R-AC, (b) E100-AC, (c) E200-AC, (d) E300-AC, and (e) E500-AC. 
TABLE 4: Textual properties of e-beam irradiated ACs.

\begin{tabular}{lcccc}
\hline Sample & Specific surface area $\left(\mathrm{m}^{2} / \mathrm{g}\right)$ & Total pore volume $\left(\mathrm{cm}^{3} / \mathrm{g}\right)$ & Micropore volume $\left(\mathrm{cm}^{3} / \mathrm{g}\right)$ & Mesopore volume $\left(\mathrm{cm}^{3} / \mathrm{g}\right)$ \\
\hline R-AC & 1924 & 0.87 & 0.76 & 0.11 \\
E100-AC & 2300 & 0.92 & 0.88 & 0.04 \\
E200-AC & 2339 & 1.02 & 0.99 & 0.03 \\
E300-AC & 2310 & 0.97 & 0.96 & 0.01 \\
E500-AC & 1902 & 0.82 & 0.79 & 0.03 \\
\hline
\end{tabular}

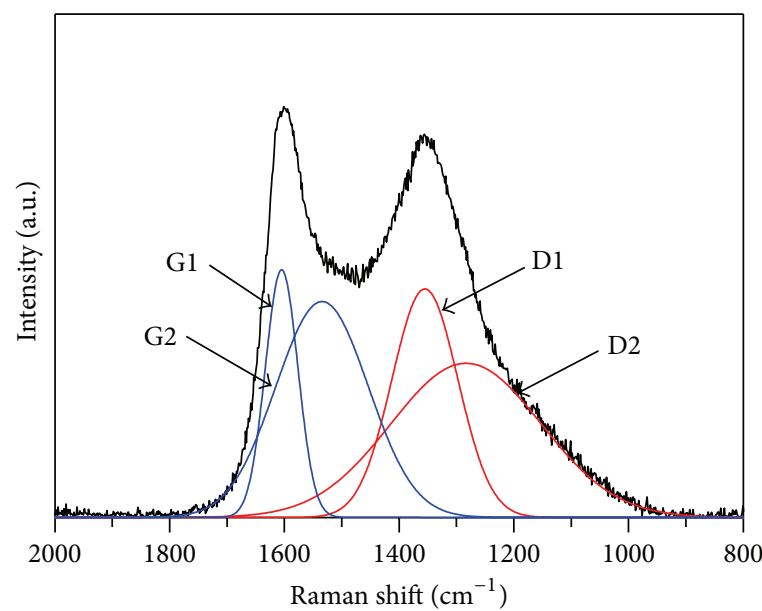

(a)

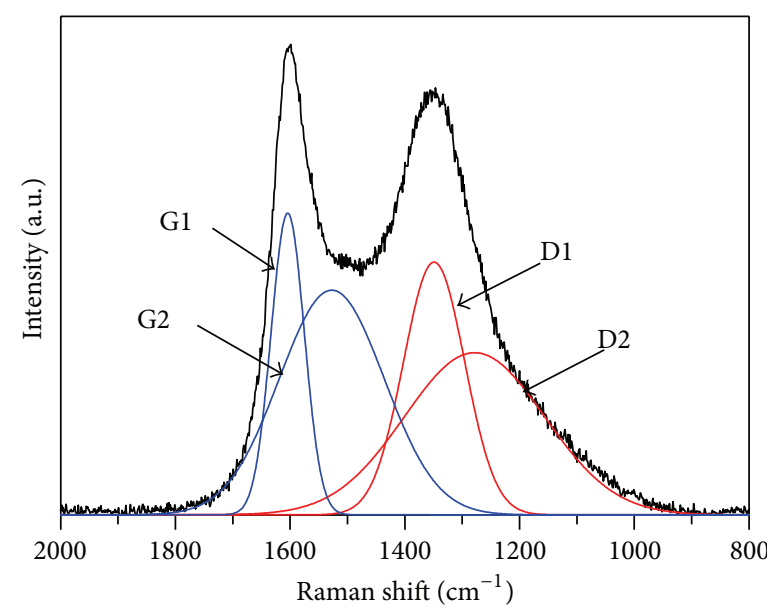

(b)

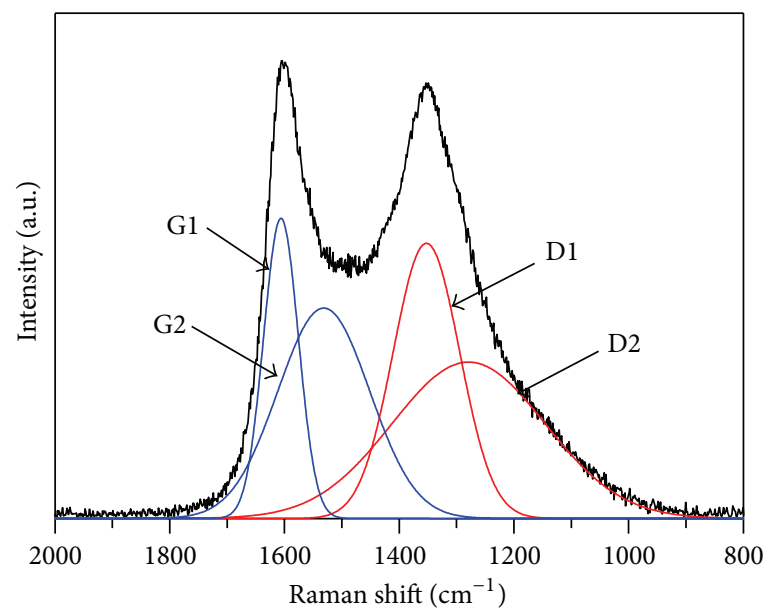

(c)

Figure 3: Raman spectra of (a) R-AC, (b) E200-AC, and (c) E500-AC.

were higher for the e-beam irradiated ACs than for R-AC, except for E500-AC. E200-AC exhibited the highest specific surface area and total pore volume $\left(2339 \mathrm{~m}^{2} / \mathrm{g}\right.$ and $1.02 \mathrm{cc} / \mathrm{g}$, resp.). These changes in textural properties indicated that the nanocrystallinity of the AC surface was transformed and degraded by the e-beam irradiation. As Raman results in Section 3.2, $I_{\mathrm{G} 2} / I_{\mathrm{G} 1}$ ratio of ACs which indicated reduction of carbon in form of clusters was decreased as increase of e-beam irradiation dose. As mentioned above, the smaller $I_{\mathrm{G} 2} / I_{\mathrm{G} 1}$ ratio led to decreasing of the carbon in forms of clusters [24]. It was expected that specific surface area of ebeam irradiated ACs could be changed by degradation of AC surface. The specific surface area of ACs was increased by appropriate e-beam irradiation dose; however, excessive irradiation dose could reduce the specific surface area of ACs due to collapse of the AC surface.

Figure 4 depicts the nitrogen adsorption isotherms of untreated and e-beam irradiated ACs. The isotherms of all samples were observed to be type I according to the IUPAC classification [27]. However, e-beam irradiated ACs seem to 


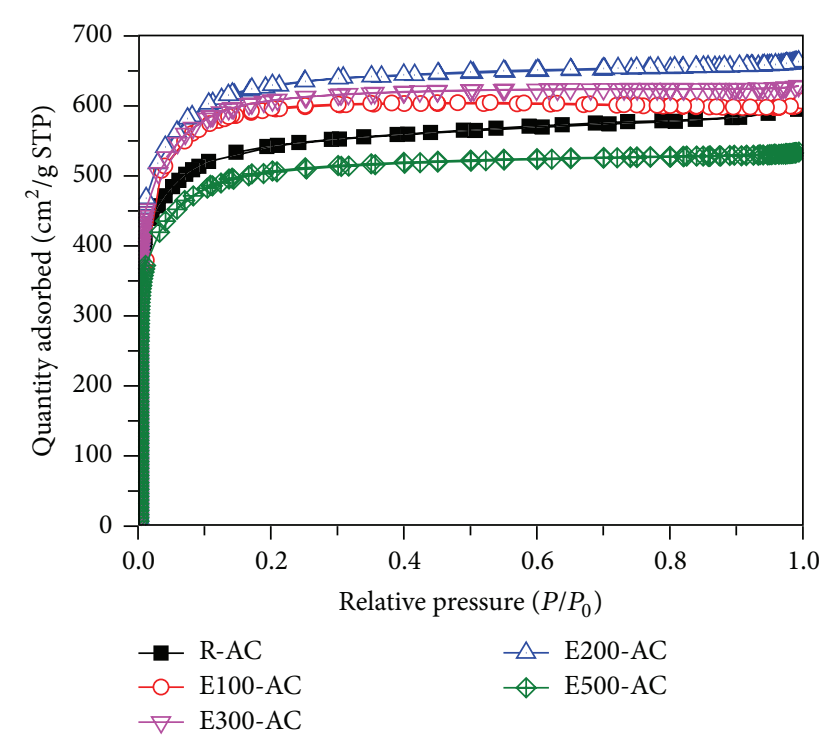

FIGURE 4: Nitrogen adsorption isotherms of e-beam irradiated ACs.

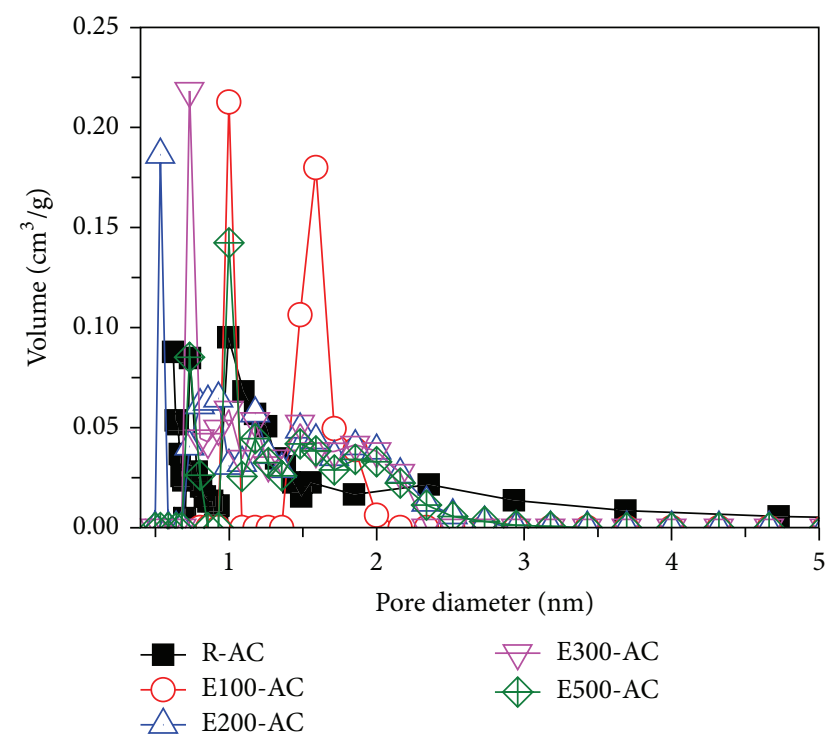

FIGURE 5: DFT pore size distribution of e-beam irradiated ACs.

be more microporous than R-AC; the adsorption of R-AC gradually increased above a $P / P_{0}$ ratio of 0.1 . Figure 5 shows the DFT pore size distribution, and it can clearly be observed that all of the samples were microporous. In addition, E100AC exhibited a larger pore volume than the other samples, with pore diameters of 1.5 to $2.0 \mathrm{~nm}$. In general, the performances of the AC-based EDLCs were determined by the textural properties of the ACs [28]. Changes in the specific surface areas, pore volumes, and pore size distributions of the ACs after e-beam irradiation were expected to improve the performances of the prepared AC-based EDLCs.

3.3. Electrochemical Properties of the E-Beam Irradiated Activated Carbons. Cyclic voltammetry (CV) was used to assess
TABLE 5: Specific capacitances of e-beam irradiated ACs.

\begin{tabular}{lcc}
\hline Sample & \multicolumn{2}{c}{ Specific capacitance $(\mathrm{F} / \mathrm{g})$} \\
& $5 \mathrm{mV} / \mathrm{s}$ & $50 \mathrm{mV} / \mathrm{s}$ \\
\hline R-AC & 247 & 157 \\
E100-AC & 277 & 257 \\
E200-AC & 306 & 262 \\
E300-AC & 250 & 229 \\
E500-AC & 169 & 161 \\
\hline
\end{tabular}

the electrochemical properties of the e-beam irradiated ACbased electrodes. Figure 6 shows the CV plots of each sample acquired at scan rates of $5 \mathrm{mV} / \mathrm{s}$ and $50 \mathrm{mV} / \mathrm{s}$. At a scan rate of $5 \mathrm{mV} / \mathrm{s}$ (Figure $6(\mathrm{a})$ ), the $\mathrm{CV}$ profiles of the ACs were approximately rectangular, and small redox peaks were observed at $0.3-0.4 \mathrm{~V}$, which indicated the occurrence of a pseudo-Faradaic reaction caused by oxygen functional groups [29]. R-AC had the highest redox peaks in this study because the $\mathrm{C}=\mathrm{O}$ bonds in the ACs were reduced by the ebeam irradiation. In the $\mathrm{CV}$ profiles of the ACs obtained at $50 \mathrm{mV} / \mathrm{s}$ (Figure 6(b)), the CVs also exhibited a rectangular shape with small redox peaks.

The discharge capacitances $(C)$ of the electrodes in the EDLCs were calculated using [30]

$$
C=\frac{1}{w \Delta V} \int_{0}^{1} i d t
$$

where $C$ is the specific capacitance of the cell in $\mathrm{F} / \mathrm{g}, w$ is the mass of the active material, $i$ is the current flowing for time $d t$, and $\Delta V$ is the potential window in which the current flows.

The calculated specific capacitances of the AC-based electrodes are listed in Table 5. In this study, E200-AC exhibited the highest specific capacitances ( 306 and $262 \mathrm{~F} / \mathrm{g}$ at scan rates of 5 and $50 \mathrm{mV} / \mathrm{s}$, resp.). The specific capacitances of the ebeam irradiated ACs increased with the e-beam irradiation dose up to $200 \mathrm{kGy}$ and then decreased. These results were expected because the specific surface areas and pore volumes of the ACs were increased by the e-beam irradiation.

Figure 7 depicts the results of the AC impedance measurements of the prepared AC-based electrodes. The charge transfer resistance $\left(R_{C}\right)$ values for R-AC, E100-AC, E200-AC, E300-AC, and E500-AC were calculated to be 1.80, 0.61, 0.56, 0.75 , and $3.84 \Omega$, respectively. The impedance results directly showed that the e-beam irradiation contributed significantly to the reduction of the charge transfer resistance of the ACs, which is in agreement with the change in electrical conductivity [31]. As mentioned above, the nanocrystallinity of the AC surfaces was increased by the e-beam irradiation. Therefore, it can be concluded that the increased nanocrystallinity of the AC surface induced by the e-beam irradiation also decreased the charge transfer resistance. However, the charge transfer resistance of the ACs increased because the nanocrystallinity of the AC surfaces was destroyed by excessive e-beam irradiation (E500-AC). The increasing charge transfer resistance of the e-beam irradiated ACs was expected because of the decrease in the specific capacitance. The charge transfer resistance was generally related to the electroactive 


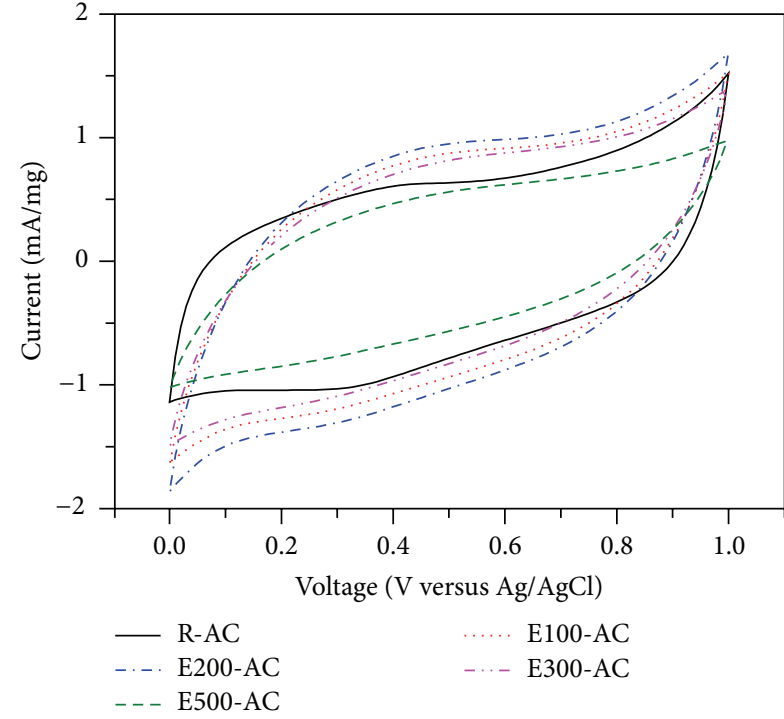

(a)

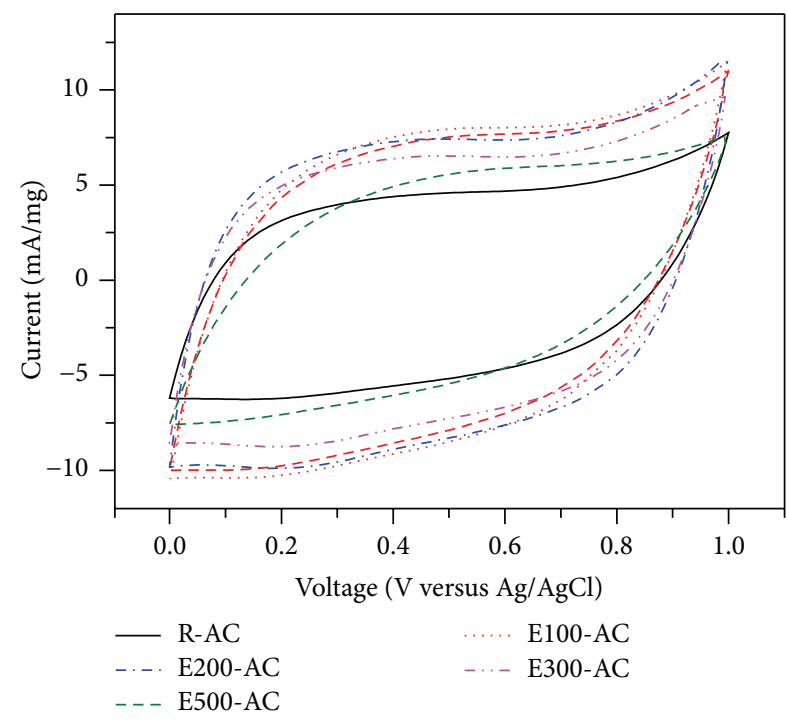

(b)

FIGURE 6: Cyclic voltammograms of e-beam irradiated ACs obtained at $5 \mathrm{mV} / \mathrm{s}$ (a) and $50 \mathrm{mV} / \mathrm{s}$ (b).

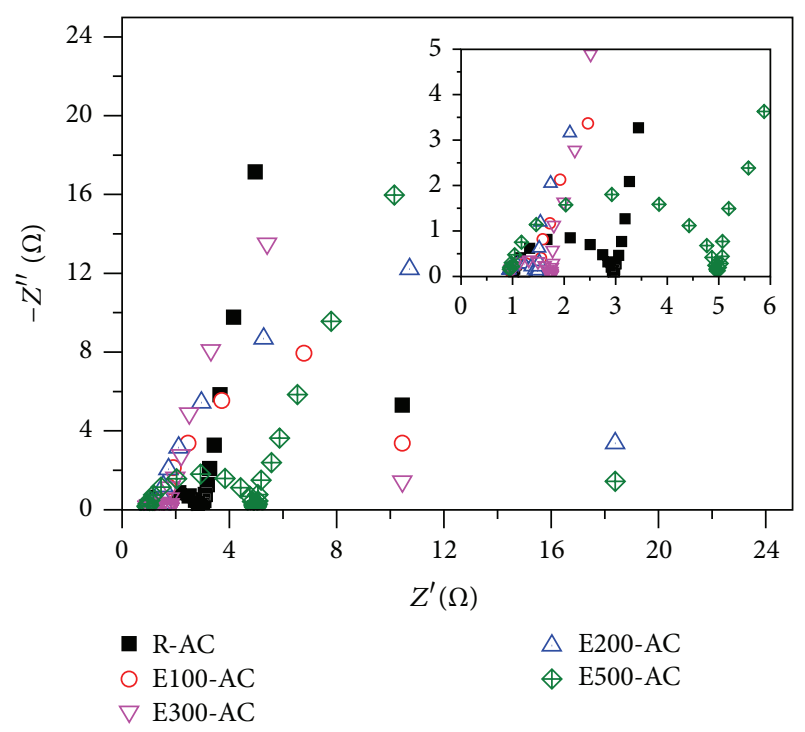

FIGURE 7: Nyquist impedance plots of e-beam irradiated ACs in $1 \mathrm{M}$ $\mathrm{H}_{2} \mathrm{SO}_{4}$ in the frequency range from $10 \mathrm{mHz}$ to $100 \mathrm{kHz}$.

surface area of the electrode materials. The electroactive surface area was a combination of the specific surface area and electrical conductivity [32]. R-AC and E500-AC had similar specific surface area, but the charge transfer resistance of E500-AC is higher than R-AC. It was expected that electrical conductivity of E500-AC decreased which causes a reduction in the specific capacitance.

\section{Conclusions}

To investigate the use of e-beam irradiation for the modification of AC surfaces, ACs were treated with e-beam irradiation. Based on the XPS results, the e-beam irradiation did not affect the chemical compositions of the AC surfaces; however, the $\mathrm{C}-\mathrm{C} \mathrm{sp} \mathrm{s}^{2}$ bonds on the AC surfaces increased as a result of the e-beam irradiation. According to the Raman results, the e-beam irradiated ACs contained lower amounts of amorphous material than the untreated AC. The specific surface areas and total pore volumes of the ACs increased after the e-beam irradiation. These changes in the chemical and textural properties indicated that the nanocrystallinity of the AC surfaces was transformed and degraded by the e-beam irradiation. Accordingly, the electrochemical properties of the ACs were enhanced by the e-beam irradiation. The specific capacitance of the AC subjected to e-beam irradiation at a dose of $200 \mathrm{kGy}$ increased by $24 \%$ relative to the untreated AC. Furthermore, the charge transfer resistance of this sample decreased from 1.80 (untreated AC) to 0.56 upon irradiation. Therefore, e-beam irradiation could be used to modify AC surfaces for electrochemical applications.

\section{Conflict of Interests}

The authors declare that there is no conflict of interests regarding the publication of this paper.

\section{Acknowledgment}

This research was supported by the National Research Foundation of Korea (NRF) funded by the Ministry of Science, ICT and Future Planning (no. 2013M2A2A6043697).

\section{References}

[1] R. L. Clough, "High-energy radiation and polymers: a review of commercial processes and emerging applications," Nuclear Instruments and Methods in Physics Research B: Beam Interactions with Materials and Atoms, vol. 185, no. 1-4, pp. 8-33, 2001. 
[2] E. H. Lee, "Ion-beam modification of polymeric materialsfundamental principles and applications," Nuclear Instruments and Methods in Physics Research, Section B: Beam Interactions with Materials and Atoms, vol. 151, no. 1-4, pp. 29-41, 1999.

[3] P. M. Mendes, S. Jacke, K. Critchley et al., "Gold nanoparticle patterning of silicon wafers using chemical e-beam lithography," Langmuir, vol. 20, no. 9, pp. 3766-3768, 2004.

[4] M. C. Cabeza, L. de la Hoz, R. Velasco, M. I. Cambero, and J. A. Ordóñez, "Safety and quality of ready-to-eat dry fermented sausages subjected to E-beam radiation," Meat Science, vol. 83, no. 2, pp. 320-327, 2009.

[5] M. M. Hassan, R. O. Aly, J. A. Hasanen, and E. S. F. El Sayed, "The effect of gamma irradiation on mechanical, thermal and morphological properties of glass fiber reinforced polyethylene waste/reclaim rubber composites," Journal of Industrial and Engineering Chemistry, vol. 20, no. 3, pp. 947-952, 2014.

[6] R. Chosdu, N. Hilmy, T. B. Erlinda, and B. Abbas, "Radiation and chemical pretreatment of cellulosic waste," Radiation Physics and Chemistry, vol. 42, no. 4-6, pp. 695-698, 1993.

[7] J. Y. Jung, M. S. Park, M. I. Kim, and Y. S. Lee, "Novel reforming of pyrolized fuel oil by electron beam radiation for pitch production," Carbon Letters, vol. 15, no. 4, pp. 262-267, 2014.

[8] J. Jung and Y. Lee, "Preparation of pitch from pyrolized fuel oil by electron beam radiation and its melt-electrospinning property," Carbon Letters, vol. 15, no. 2, pp. 129-135, 2014.

[9] D. Teweldebrhan and A. A. Balandin, "Modification of graphene properties due to electron-beam irradiation," Applied Physics Letters, vol. 94, no. 1, Article ID 013101, 2009.

[10] W. Ding, D. A. Dikin, X. Chen et al., "Mechanics of hydrogenated amorphous carbon deposits from electron-beaminduced deposition of a paraffin precursor," Journal of Applied Physics, vol. 98, no. 1, Article ID 014905, 2005.

[11] S. Gupta and R. J. Patel, "Changes in the vibrational modes of carbon nanotubes induced by electron-beam irradiation: resonance Raman spectroscopy," Journal of Raman Spectroscopy, vol. 38, no. 2, pp. 188-199, 2007.

[12] F. Solá, "Electrical properties of pristine and electron irradiated carbon nanotube yarns at small length scales," Modern Chemistry \& Applications, vol. 2, no. 1, p. 116, 2014.

[13] A. Qiu and D. F. Bahr, "Modification of the mechanical properties of carbon nanotube arrays using electron irradiation induced oxidation," Meccanica, vol. 50, no. 2, pp. 575-583, 2014.

[14] S. Prawer and R. Kalish, "Ion-beam-induced transformation of diamond," Physical Review B, vol. 51, no. 22, pp. 15711-15722, 1995.

[15] M. Slouf, H. Synkova, J. Baldrian et al., "Structural changes of UHMWPE after e-beam irradiation and thermal treatment," Journal of Biomedical Materials Research Part B: Applied Biomaterials, vol. 85, no. 1, pp. 240-251, 2008.

[16] S. H. Kim, Y. J. Noh, S. N. Kwon et al., "Efficient modification of transparent graphene electrodes by electron beam irradiation for organic solar cells," Journal of Industrial and Engineering Chemistry, 2014.

[17] L. E. Cruz-Barba, S. Manolache, and F. Denes, "Novel plasma approach for the synthesis of highly fluorinated thin surface layers," Langmuir, vol. 18, no. 24, pp. 9393-9400, 2002.

[18] S. Yuan, S. O. Pehkonen, B. Liang, Y. P. Ting, K. G. Neoh, and E. T. Kang, "Superhydrophobic fluoropolymer-modified copper surface via surface graft polymerisation for corrosion protection," Corrosion Science, vol. 53, no. 9, pp. 2738-2747, 2011.
[19] R. V. Gelamo, R. Landers, F. P. M. Rouxinol et al., "XPS investigation of plasma-deposited polysiloxane films irradiated with helium ions," Plasma Processes and Polymers, vol. 4, no. 4, pp. 482-488, 2007.

[20] S. Karthikeyan, K. Viswanathan, R. Boopathy, P. Maharaja, and G. Sekaran, "Three dimensional electro catalytic oxidation of aniline by boron doped mesoporous activated carbon," Journal of Industrial and Engineering Chemistry, vol. 21, pp. 942-950, 2015.

[21] F. Banhart, "Irradiation effects in carbon nanostructures," Reports on Progress in Physics, vol. 62, no. 8, pp. 1181-1221, 1999.

[22] J. Qiu, Y. Li, Y. Wang, C. Liang, T. Wang, and D. Wang, "A novel form of carbon micro-balls from coal," Carbon, vol. 41, no. 4, pp. 767-772, 2003.

[23] Y. Zhang, Y. Tang, L. Lin, and E. Zhang, "Microstructure transformation of carbon nanofibers during graphitization," Transactions of Nonferrous Metals Society of China, vol. 18, no. 5, pp. 1094-1099, 2008.

[24] J. Sreńscek-Nazzal and B. Michalkiewicz, "The simplex optimization for high porous carbons preparation," Polish Journal of Chemical Technology, vol. 13, no. 4, pp. 63-70, 2011.

[25] J. Li and F. Banhart, "The engineering of hot carbon nanotubes with a focused electron beam," Nano Letters, vol. 4, no. 6, pp. 1143-1146, 2004.

[26] S. Gupta, R. J. Patel, N. Smith, R. E. Giedd, and D. Hui, "Room temperature dc electrical conductivity studies of electron-beam irradiated carbon nanotubes," Diamond and Related Materials, vol. 16, no. 2, pp. 236-242, 2007.

[27] S. J. Gregg and K. S. W. Sing, Adsorption Surface Area and Porosity, Academic Press, London, UK, 2nd edition, 1982.

[28] O. Barbieri, M. Hahn, A. Herzog, and R. Kötz, "Capacitance limits of high surface area activated carbons for double layer capacitors," Carbon, vol. 43, no. 6, pp. 1303-1310, 2005.

[29] S. R. S. Prabaharan, R. Vimala, and Z. Zainal, "Nanostructured mesoporous carbon as electrodes for supercapacitors," Journal of Power Sources, vol. 161, no. 1, pp. 730-736, 2006.

[30] M. Ramani, B. S. Haran, R. E. White, and B. N. Popov, "Synthesis and characterization of hydrous ruthenium oxidecarbon supercapacitors," Journal of the Electrochemical Society, vol. 148, no. 4, pp. A374-A380, 2001.

[31] N. G. Tsierkezos, P. Szroeder, and U. Ritter, "Multi-walled carbon nanotubes as electrode materials for electrochemical studies of organometallic compounds in organic solvent media," Monatshefte für Chemie, vol. 142, no. 3, pp. 233-242, 2011.

[32] M.-S. Wu and H.-H. Hsieh, "Nickel oxide/hydroxide nanoplatelets synthesized by chemical precipitation for electrochemical capacitors," Electrochimica Acta, vol. 53, no. 8, pp. 3427-3435, 2008. 

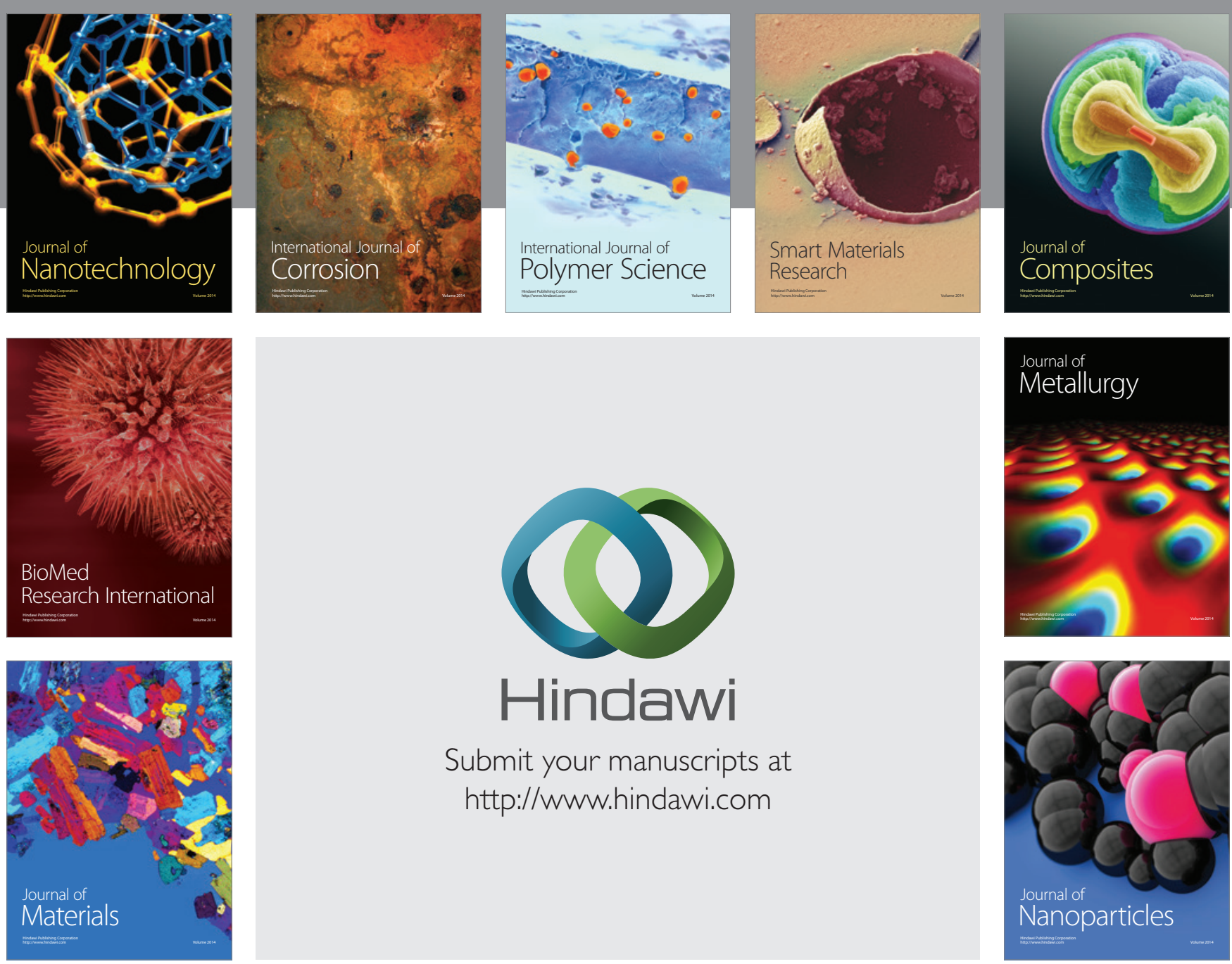

Submit your manuscripts at http://www.hindawi.com
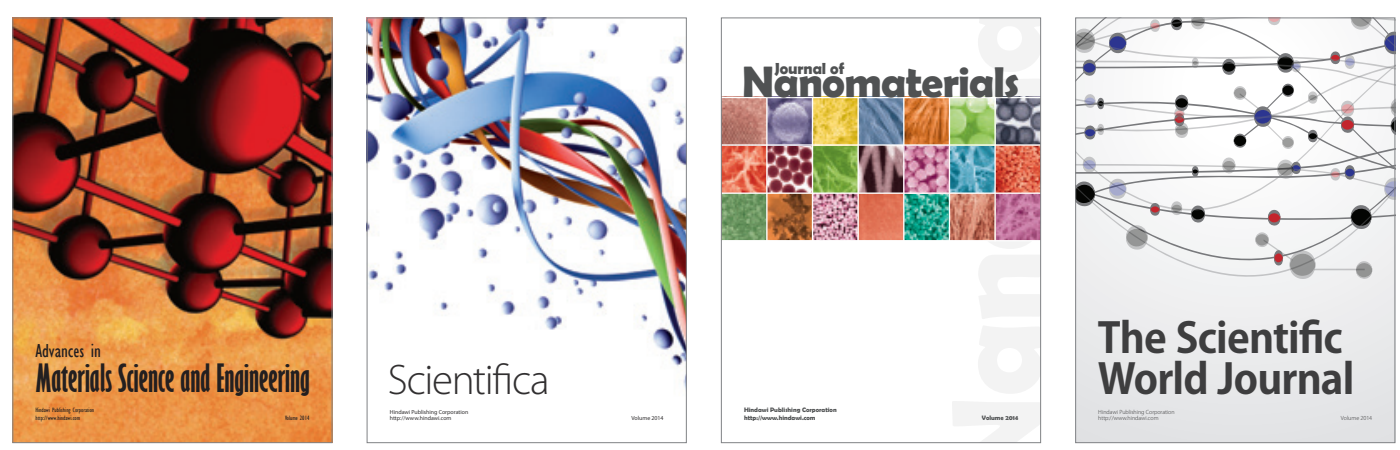

\section{The Scientific World Journal}
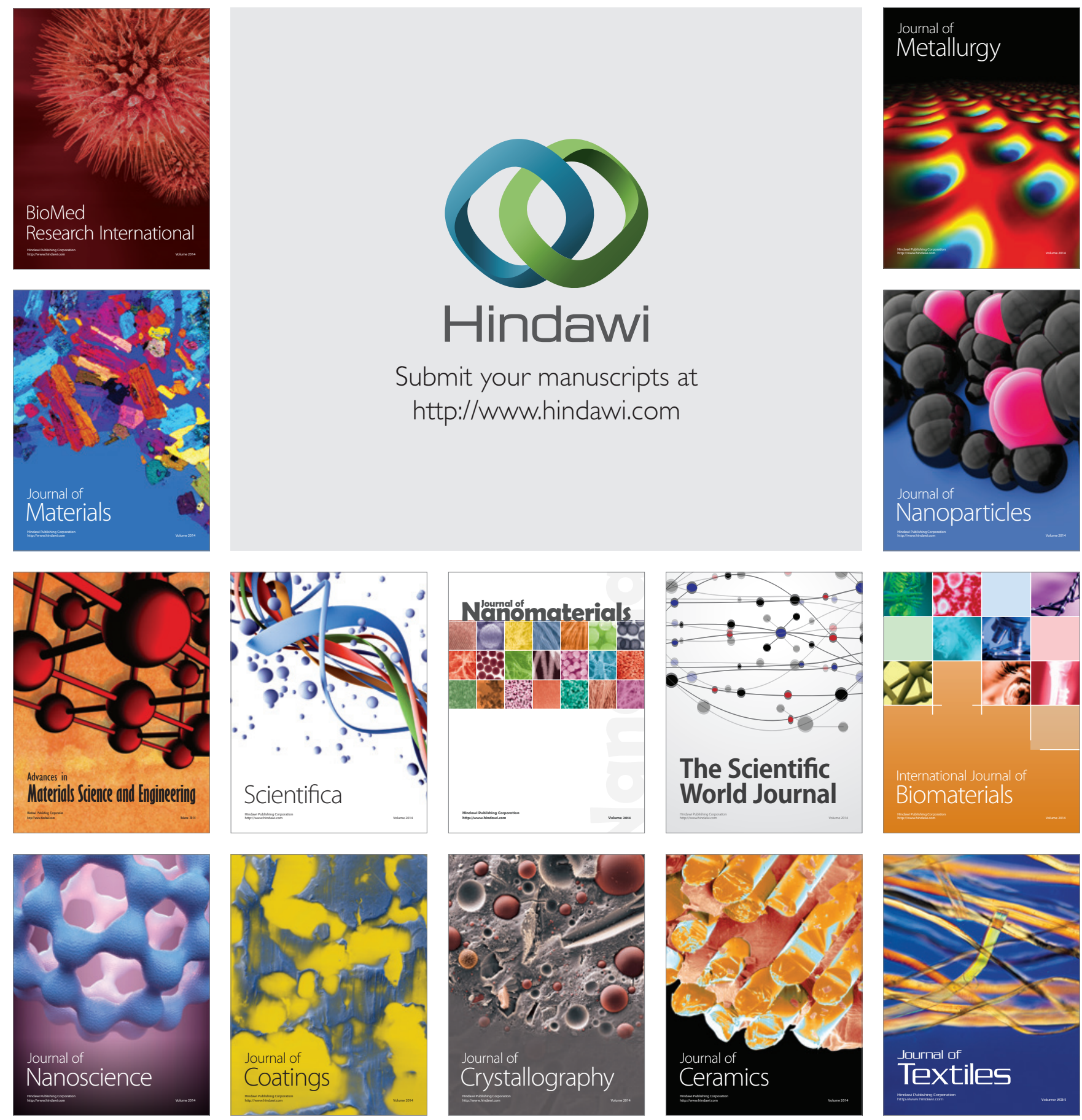